\title{
Environmental sustainability assessment of organic vineyard practices from a life cycle perspective
}

\author{
Mirco Volanti $^{1,2} \cdot$ C. Cubillas Martínez ${ }^{3,4} \cdot$ D. Cespi ${ }^{1}$ (I) $\cdot$ E. Lopez-Baeza ${ }^{3} \cdot$ I. Vassura $^{1,2} \cdot$ F. Passarini $^{1,2}$
}

Received: 23 December 2020 / Revised: 23 August 2021 / Accepted: 20 September 2021 / Published online: 18 October 2021

(c) The Author(s) 2021

\begin{abstract}
Due to increased awareness of the current and future issues with the environment, sustainable development has become a well-known concept and goal in the last decades. Based on this idea, organic agriculture is now fairly generalized in many farms and grape processing factories. Life cycle assessment (LCA) represents a valuable and standardized technique to evaluate how sustainable a crop can become, determining the potential impacts that the complete-life product causes on the environment and on the management/conservation of resources. Although LCA can be applied to any product, this work focusses on organic grapevine crops as the subject of study, in order to improve energy and water efficiency and minimizing issues such as the use of pesticides. This paper, collecting primary data from three Spanish grape processing factories, quantifies the reduction of the overall impact related to the avoidance of artificial irrigation, amounting to $10 \%$, and the saving of resources ( $-4.3 \mathrm{~kg}$ oil eq. per ha) due to the replacement of chemical fertilisers with animal manure. On the other hand, the use of manure has shown some controversy from an environmental point of view as it contributes to global warming, resulting in an increase in the total impact of the organic vineyard. As predictable, the application of conventional practices as well as the use of water for irrigation could both result in a higher overall yield, and in a contemporary growth of environmental impacts; a discussion about the quantification of this aspect is also inserted.
\end{abstract}

Keywords Agricultural LCA · Environmental sustainability · Grapevine · Organic agriculture $\cdot$ Resources conservation

\section{Introduction}

Editorial responsibility: Samareh Mirkia.

D. Cespi

daniele.cespi2@unibo.it

1 Department of Industrial Chemistry “Toso Montanari”, University of Bologna, viale del Risorgimento 4, 40136 Bologna, Italy

2 Interdepartmental Centre of Industrial Research "Renewable Sources, Environment, Blue Growth, Energy”, University of Bologna, via Angherà 22, 47921 Rimini, Italy

3 Department of Earth Physics \& Thermodynamics, Climatology From Satellites Group, University of Valencia, C/ Dr. Moliner 50, Burjassot, 46100 Valencia, Spain

4 South Oxfordshire and Vale of White Horse District Councils, 135 Eastern Avenue, Milton Park, Abingdon SO14 4SB, Oxfordshire, UK
The term sustainable agriculture refers to the agricultural sector based on understanding of ecosystem services that consider all the relationships between organisms and their environment (Gold 1999). In general, sustainable agriculture encourages integrated systems that enhance environmental quality and the natural resource base upon which agricultural economy depends and makes the most efficient use of non-renewable resources and water as well. Amongst the many practices that comprise sustainable agriculture, one of the most significant is organic agriculture (Falk 2013). It is defined as a "system aiming at producing food with minimal harm to ecosystems, animals or humans" (Seufert et al. 2012), thus avoiding or minimizing the use of synthetically compounded fertilisers, pesticides, growth regulators and relying upon crop residues, animal and green manures, and mineral-bearing rocks to maintain soil productivity (USDA 1980) to a maximum extent. In addition, organic agricultural practices are internationally regulated and legally enforced by many nations, thanks to which organic food market has 
grown rapidly, surpassing the $\$ 100$ billion thresholds for the first time in 2018 (Willer et al. 2020).

Organic agricultural practices are applied in the production both of food and beverage, and, amongst the latter, grape processing factories represent one of the most significant and promising sectors. Nowadays, almost $70 \%$ of the grape processed products worldwide commercialized is made in Europe, being France, Italy and Spain the most significant producers (de Pablo Valenciano and Román Sánchez 2011). European grape processed market depends mostly on the D.O.P. (Protected Designations of Origin) system (EU 510/2006), which states that "the geographical name of a country, region or locality serves to designate a product as originating therein, the quality or characteristics of which are exclusively or essentially due to the geographical environment, including natural or human factors" (Moran 1993; Holland and Smit 2010). The D.O.P. system is, therefore, used as a warranty of quality of the Spanish and European grape processed products, but not the only one. Consumers pay attention to certain attributes of the products and have a growing appreciation for some characteristics, such as being organic (Marette 2005). However, even if organic, the production of grape processed products, as well as all the anthropogenic activities, is not free of several environmental loads.

The aim of this study is to have an estimation of the whole environmental sustainability of grape processing factories by considering different agricultural practices that normally occur. For this purpose, three different vineyards were selected as case studies. On the one hand, two of them (from now on called Scenario A and Scenario B, respectively) are located in the region of Valencia, within the Utiel-Requena D.O.P., both using organic grape growing methodologies (e.g. rainfed vines and using manure). On the other hand, the third (Scenario C) is a smaller vineyard, located in the Tierra de Leon D.O.P. (Castilla y Leon region), which produces grapes following the conventional (non-organic) cultivation methods with low concentration of pesticides.

In order to address environmental sustainability, a life cycle approach was used to evaluate whether these cultivation methodologies were actually different in terms of management and conservation of resources and avoiding impacts to the environment. Attempts to improve the environmental performance of vineyards have usually been mostly focussed on energy and water efficiency (Román Sánchez and Belmonte-Ureña 2013; Civit et al. 2018) and localized issues such as pesticide reduction (Marshall et al. 2005) and their spread (Otto et al. 2015). The target of this study is, therefore, to collect primary data from different grape processing factories and quantify how much vine crops that are irrigated and those that have a greater use of pesticides or fertilisers will have a higher ecological footprint than those non-irrigated and without pesticides or fertilisers. The results of this study could suggest grape processing factories to implement more sustainable alternatives that translate into reducing the impacts their vineyards cause to the environment. This is possible through the application of the life cycle assessment (LCA) methodology, which not only evaluates environmental impacts, but also identifies the processes or actions that cause larger harm to the environment.

\section{Materials and methods}

LCA is a well-known methodology able to evaluate the environmental sustainability of a process, product or system, within its entire life cycle. It is standardized by the ISO 14040-14044 series (ISO 2006a; b), which defines four conceptual stages: ( $i$ ) goal and scope definition, (ii) life cycle inventory (LCI), (iii) life cycle impact assessment and (iv) interpretation. In this study, the first two phases (goal and scope definition and LCI) are included in the "Materials and methods" section and the next two (life cycle impact assessment and interpretation) in the "Results and discussion" section.

LCA is a highly versatile methodology, which finds application in different production sectors, it can be used for the evaluation of entire industrial systems (Zhao et al. 2018; Sabeen et al. 2019) or individual products (Peters et al. 2017; Cano Londoño et al. 2019), it can involve the study of new technologies (Lacirignola et al. 2017; van der Giesen et al. 2020) or the improvement of existing ones (Mohammadi and South 2017; Neri et al. 2018); moreover, it can also be applied both on an industrial (Cespi et al. 2016; Piccinno et al. 2018) and laboratory (Ricciardi et al. 2017; Tsapekos et al. 2019) scale to address sustainability in various fields. Its use has naturally reached also agricultural studies, with a particular focus on biological systems, as shown by the numerous recent works carried out on the subject (Quirós et al. 2015; Clark and Tilman 2017; Brockmann et al. 2018; Trinh et al. 2020; Avadí 2020; Jezierska-Tys et al. 2020).

The application of LCA analysis in the sector of grape processed products is not new. Several international studies have confirmed its importance as harmonized tool (standalone or combined with other methodologies) to evaluate sustainability within the agricultural (Dantsis et al. 2010; Liang et al. 2019) and grape processing factories (Comandaru et al. 2012; Stoessel et al. 2012; Arzoumanidis et al. 2014; Iannone et al. 2016), also considering different countries, such as Spain (Aranda et al. 2005; Gazulla et al. 2010), 
Italy (Notarnicola et al. 2003; Pizzigallo et al. 2008; Benedetto 2013), United States (Hillis et al. 2018) or Canada (Point et al. 2012). In this manuscript, LCA is used to evaluate the potential environmental loads of different agricultural practices in the cultivation of grapes (wine production from grapes was voluntarily excluded being considered non-relevant for the aim of the study). The main idea of this research is to guide little grape processing factories (where the potential for improvement is greatest) towards more sustainable practices supporting their choices during the whole chain through a simplified and repeatable analysis.

The chosen software to carry out this study was SimaPro v9.1 (PRé Consultants 2020), together with some of the most suitable database and analysis methods for the purpose of this study. AGRIBALYSE v3.0 database (Koch and Salou 2016) has been selected as the reference library to complete the inventory analysis for the background data as it is particularly suited to helping the agricultural sector to improve its practices (Colomb et al. 2015). The ReCiPe 2016 method (Huijbregts et al. 2016) was chosen to analyse the scenarios since it is able to evaluate and quantify the environmental impacts of the practices (midpoint level), and consider the effect that these cause (endpoint level). In these years, some environmental indicators were identified as the most common indexes to express sustainability within the grape processed products sector, for instance, carbon footprint (Rugani et al. 2013; Villanueva-Rey et al. 2014). On the other hand, impact categories such as eco-toxicity related to the field emissions of pesticides (Renaud-Gentié et al. 2015), land use and land-use changes (Villanueva-Rey et al. 2015) or water quality (Herath et al. 2013) have been less studied due to the lack of data. Here in this manuscript, more than one index has been considered with the aim of considering a broader range of impacts.

In this study, a cradle-to-farm gate perspective was applied, including all the processes from the resource extraction (e.g. water) up to the grape production. All processes involved in the entire production chain were considered, including the production of energy, chemicals, fertilisers/pesticides, fuels, transportation and machinery application (e.g. tractors). However, all stages that occur after the grapes' harvest were voluntarily omitted, since they were outside the scope of this research. Figure 1 depicts a schematic view of the system boundaries considered.

In order to simulate the cultivation procedure, 1 ha of grapevine crop was selected as functional unit (FU) to refer all the input and output flows which characterize the system under study. This FU was selected to properly understand the contribution of many variables on the total impacts, deriving from different agricultural practices on the same land extension, coherently with the LCA's purpose. Aware that the productivity of an organic vineyard may be lower than that of a conventional one, in this study a production of $+20 \%$ per hectare was assigned to the conventional vineyard (Scenario C), as reported in literature (Malusà et al. 2004; Borsato et al. 2020). This is the lowest yield value obtained from an organic crop compared to the conventional one (the reported mean is $10-11 \%$ ) and here it is used to consider the worst possible scenario for organic practices, in order to give more robustness to the results of the analysis. To do this, all inputs and outputs (and therefore impacts) of Scenario $\mathrm{C}$ are referred to 0.80 ha instead of 1 ha. In this

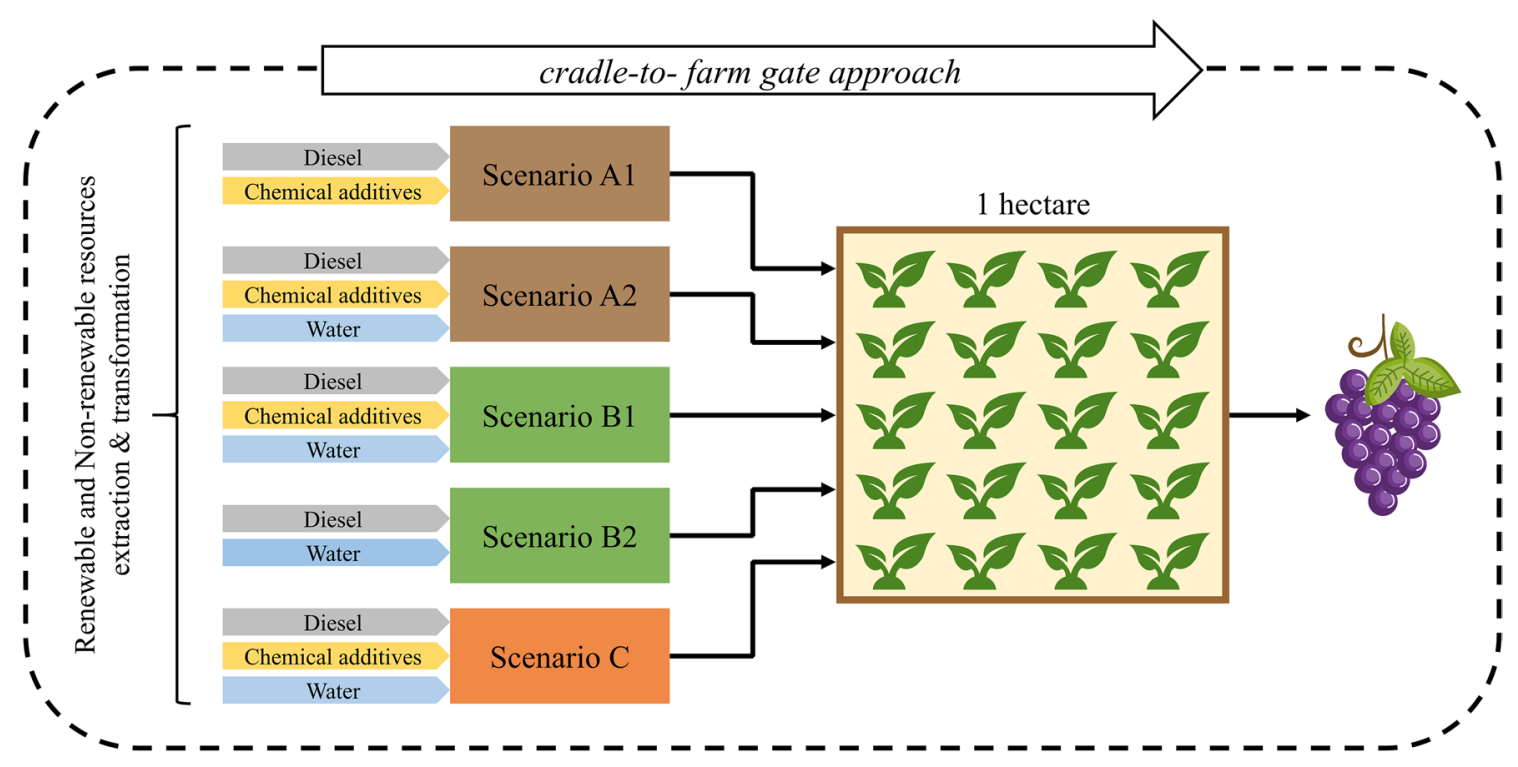

Fig. 1 System boundaries of the study: cultivation of 1 hectare of land to produce grapes 
study, we prefer to keep a wide range between the yields of the two crops, in order to take into account any territorial and grape quality variations that might occur elsewhere or in certain seasons. On the other hand, no difference in yield is considered for the comparison between cultivation with or without irrigation, or with manure or chemical fertilisers, as these scenarios are not as standardisable. However, this will be discussed later in the analysis of the results.

Published LCA studies on grape processed production have highlighted the importance of obtaining significant onsite data for the processes included in the system (Petti et al. 2010; Sinisterra-Solís et al. 2020), because the more realistic the data, the higher will be the quality of the study. Therefore, only primary data directly furnished by the farmers' companies were adopted to complete the LCI phase. From the data provided by the three grape processing factories, five scenarios were created to analyse the environmental burdens of the different used techniques:

- Scenario A1: is the part of the Scenario A which was rainfed;

- Scenario A2: is the part of the Scenario A which was irrigated;

- Scenario B1: is the cultivation of the Scenario B in which fertilisers were used;

- Scenario B2: is the cultivation of the Scenario B in which animal manure was used to replace fertilisers;

- Scenario C: describes the current situation of a small and conventional production, used as benchmark to evaluate the environmental results from the organic grape processing factories.

For each identified scenario, a model was built on the software with which the environmental performance of the grape processing factories is evaluated. The complete LCI is shown in Table 1. As indicated earlier and shown in table, the main difference between the practices in use in Scenario A is that part of the vineyard is rainfed (Scenario A1) and the rest is irrigated (Scenario A2). Scenario A1 requires water for dissolving and spreading pesticides but not for irrigation, so it will be the benchmark for estimating the environmental effects of water extraction and pumping, which in turn are assessed in Scenario A2. In Scenario A the main inputs are diesel used for land working machines (cultivator, atomizer, harvest tractor, transportation, etc.) and the chemical additives. The vineyard uses Cuprocol ${ }^{\circledR}$ (described as copper oxide since it is its main component) and sulphur, as inorganic additives, and Armicarb ${ }^{\circledR}$ as an organic potassium oxide pesticide. Since both parts of vine crops are cultivated following the same agricultural practices all input quantities are the same, with the only difference that in Scenario A2 the consumption of diesel fuel for the extraction of water needed for irrigation has been included.

As for the two scenarios that simulate the different cultivation practices applied in the Scenario B, the difference is in the type of fertiliser used. In particular, while a bio-based fertiliser, extracted from marine algae (Algagreen $\left.{ }^{\circledR}\right)$, was used in Scenario B1, animal manure was applied in Scenario B2. Around 20 tonnes of animal manure, as shown in Table 1, are used per hectare. In addition to algae, Scenario B1 compared to B2 has the use of Aton $\mathrm{K} \circledR$ (a potassium oxide-based fertiliser) and a higher demand for sulphur (the main component of Cepsul® pesticide) and water, which is needed to dissolve the increased amount of additives. The use of diesel for agricultural machinery is the same in both scenarios, as they were used according to the same identical procedures. In order to evaluate the impact of animal manure of Scenario B2, a process from the AGRIBALYSE database
Table 1 Life Cycle Inventory of the considered scenarios in the study

\begin{tabular}{lllllll}
\hline Substance & Unit & Scenario A1 & Scenario A2 & Scenario B1 & Scenario B2 & Scenario C \\
\hline Algagreen® & $\mathrm{kg}$ & - & - & 1.10 & - & - \\
Armicarb® & $\mathrm{kg}$ & 1.28 & 1.28 & - & - & - \\
Aton K® & $\mathrm{kg}$ & - & - & 0.43 & - & - \\
Cabrio® Top & $\mathrm{kg}$ & - & - & - & - & 0.90 \\
Collis® & $\mathrm{kg}$ & - & - & - & - & 0.01 \\
Cuprocol® & $\mathrm{kg}$ & 1.50 & 1.50 & - & - & 1.31 \\
Diesel for machinery & $\mathrm{kg}$ & 55.98 & 55.98 & 5.89 & 5.89 & 5.61 \\
Diesel for water extraction & $\mathrm{kg}$ & - & 10.10 & - & - & - \\
Grytos® & $\mathrm{kg}$ & - & - & - & - & 1.35 \\
Manure & $\mathrm{kg}$ & - & - & - & 20,000 & 5,000 \\
Sulphur & $\mathrm{kg}$ & 81.85 & 81.85 & 55.40 & 35.70 & 1.12 \\
Superphosphate & $\mathrm{kg}$ & - & - & - & - & 300 \\
Water & 1 & 2500 & 30,000 & 4.90 & 4.30 & 1750 \\
\hline
\end{tabular}


was chosen, but the impacts related to the production of the fed that is given to the animals were excluded. The feed, in fact, is given to animals for the purpose of obtaining products (such as meat, milk, fat, etc.), while manure can be considered as waste. The result of a specific analysis on manure (reported in Table S1 in Supplementary Information) shows that feed production has a significant weight, so, although the baseline scenario is the one in which it is excluded, the discussion of the results will also consider these impacts. Other impacts concerning animal management and manure emissions are included in the system boundaries.

Scenario C represents the case of a small and conventional grape processing factory where no organic practices are applied. The full LCI, also in this case directly completed by the owners, is reported in Table 1. It includes the input water used to dissolve the main chemical substances used. Amongst these, some pesticides such as Grytos ${ }^{\circledR}$ (described in the model as glyphosate which is the main component), Cuprocol ${ }^{\circledR}$ (described as copper oxide), Cabrio ${ }^{\circledR}$ Top (described as metiram and pyraclostrobin) and Collis ${ }^{\circledR}$ (which is defined by boscalid and kresoxim-methyl). This scenario also included the use of sulphur (further pesticide) and diesel to fuel all the machinery.

\section{Results and discussion}

Of the sixteen categories that the ReCiPe method includes, seven were selected as the most representative of the analysis: global warming $(\mathrm{GW})$, fine particulate matter formation (FPMF), terrestrial acidification (TA), human toxicity (HT), fossil resource scarcity (FRS) and water consumption (WC). These are the categories that have shown a contribution of at least $1 \%$ to the overall impact of all scenarios and the results are shown in Table 2 . The full results of the scenarios, including all other categories, are given in Table S2 in supplementary information. First, each vine is discussed separately in order to highlight the inter-scenario differences of grape processing factories $\mathrm{A}$ and $\mathrm{B}$. Then a comparison between the agricultural practices of the three considered cases is carried out.

\section{Scenario A}

As shown in Table 2, in general, no significant differences are observed between the two scenarios of Scenario A. This is due to the similarities in the cultivation method, which only differ in the use of water for irrigation (Scenario A2)
Table 2 Impacts of all considered scenarios in terms of ReCiPe 2016 Midpoint H/A

Fig. 2 Contribution analysis of Scenario A1 and Scenario A2 (ReCiPe 2016 Midpoint)

\begin{tabular}{llccccc}
\hline Impact category & Unit & Scenario A1 & Scenario A2 & Scenario B1 & Scenario B2 & Scenario C \\
\hline $\mathrm{GW}$ & $\mathrm{kg} \mathrm{CO}_{2} \mathrm{eq}$ & 438.3 & 475.9 & 57.4 & 289.3 & 481.0 \\
FPMF & $\mathrm{kg} \mathrm{PM}_{2.5}$ eq & 1.2 & 1.4 & 0.1 & 0.3 & 2.1 \\
$\mathrm{TA}$ & $\mathrm{kg} \mathrm{SO}_{2} \mathrm{eq}$ & 2.5 & 2.8 & 0.3 & 1.6 & 5.5 \\
$\mathrm{HT}$ & $\mathrm{kg} \mathrm{1,4-DCB}$ & $2,455.6$ & $2,457.9$ & 167.5 & 231.1 & 2524.7 \\
FRS & $\mathrm{kg} \mathrm{oil} \mathrm{eq}$ & 174.8 & 187.3 & 49.1 & 44.8 & 168.5 \\
WC & $\mathrm{m}^{3}$ & 5.1 & 32.7 & 0.3 & 0.9 & 17.5 \\
\hline
\end{tabular}
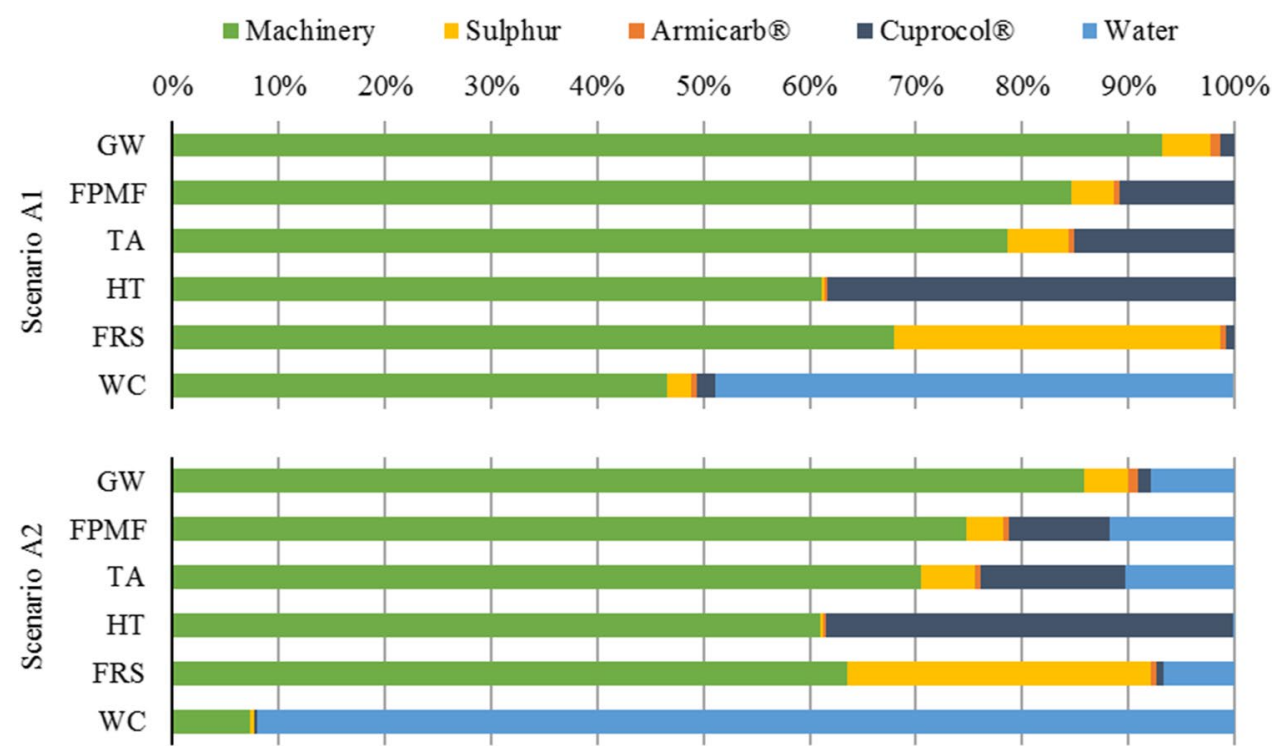
or the lack of it (Scenario A1). As stated above, it is initially assumed that there is no difference in productivity in the two cases. The impact category in which these two parts of the vineyard A strongly differs is then WC, where the total footprint achieved by Scenario A2 is about six times greater than that of Scenario A1. The other differences detected between the two scenarios (approximately $+10 \%$ of Scenario A2 compared to Scenario A1) are mainly due to the embodied impact of the different amount of water extracted. However, in order to understand the weight of each input/output flow on the impact of midpoint categories, a contribution analysis was carried out, shown in Fig. 2.

The results presented in Fig. 2 confirm that most (>92\%) of the impact of WC category for Scenario A2 is due to water extraction for irrigation; the remaining $8 \%$ is embodied water (e.g. energy and fuels production, chemical auxiliaries supply chain, etc.). On the other hand, in Scenario A1 the situation is more balanced, as since less water is used its weight falls to $49 \%$, while the contribution from the use of diesel for agricultural machinery gains importance. In GW, FPMF, TA and FRS impact categories the use of water for irrigation shows contributions ranging from 7 to $12 \%$ of the total of Scenario A2, while in the HT category its weight is almost zero.

The contribution analysis of the other inputs shows that the use of agricultural machinery is the main responsible for the impacts. The largest contribution is in the GW category, where it accounts for $93 \%$ and $86 \%$ of the impacts of Scenario A1 and Scenario A2, respectively. In the FPMF and TA impact categories, its contribution varies between 79 and $85 \%$ for Scenario A1 and $71-75 \%$ for Scenario A2, while in HT and FRS its weight decreases but always remains above $60 \%$. Therefore, it is clear that the management and use of agricultural machinery plays a fundamental role in the life cycle assessment of Scenario A. As for the additives used in this crop, sulphur shows particularly important impacts in the FRS category, where it covers about $30 \%$ of the impacts of the scenarios due to the use of natural gas during its production chain. In the other categories, however, its contribution does not exceed 5-6\% of the total. On the other hand, Cuprocol ${ }^{\circledR}$ seems to have a higher overall weight, $10-15 \%$ in the FPMF and TA categories and even around $40 \%$ in the HT category. In the latter category, its impact is due to the sulphidic tailings produced during copper manufacturing, whose environmental criticalities linked to toxicity have already been investigated (Beylot and Villeneuve 2017). Finally, it is noted that the contribution of the organic pesticide Armicarb ${ }^{\circledR}$ does not exceed $1 \%$ of the impacts of the categories.

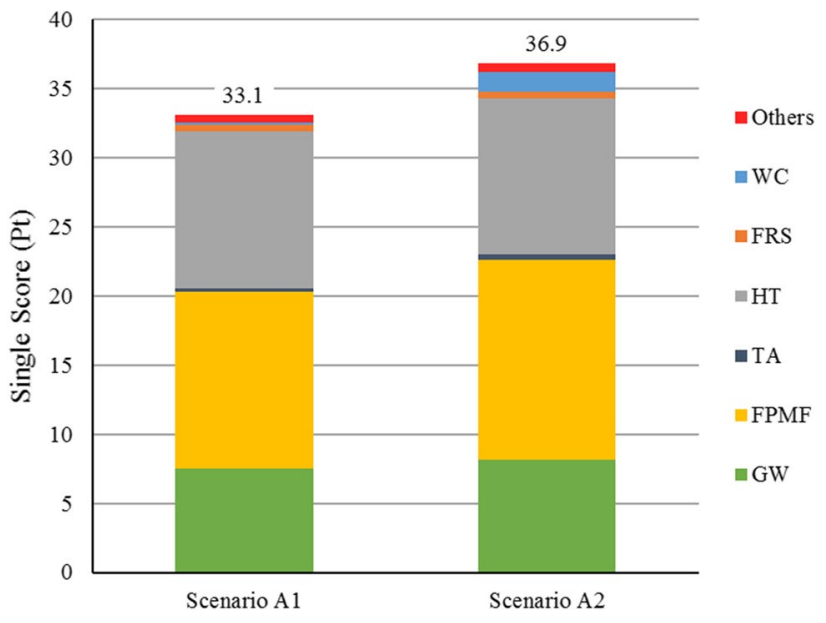

Fig. 3 Single Score results for Scenario A1 and Scenario A2 (ReCiPe 2016 Endpoint H/A)

In order to understand how much each impact category influences the environmental weight of the scenarios and to quantify their overall impact, an endpoint level analysis was conducted. Results presented in Table 2 have been normalized and weighed to obtain a Single Score that allows the comparison between different categories. This procedure, which is provided by the ReCiPe method, uses specific normalization factors to convert impact category units into points $(\mathrm{Pt})$. Also in this analysis, only the results of the most important categories will be shown, while in the Supplementary Information the full results can be found, divided by impact category (Table S3) and by input (Table S4). Results for the Scenario A scenarios are shown in Fig. 3.

As also suggested by the midpoint analysis, Fig. 3 shows that Scenario A2 has a greater overall impact as Scenario $\mathrm{A} 1,36.9 \mathrm{Pt}$ and $33.1 \mathrm{Pt}$, respectively. The results indicate that FPMF category is the one with the greatest responsibility for the impact, around $40 \%$ of the total, followed by HT (responsible for 31-34\%) and GW (around 22\%). These three categories cover almost all the impact of the scenarios, i.e. $95 \%$ of Scenario A1 and $92 \%$ of Scenario A2, and therefore need to be particularly considered in order to reduce the total environmental burden. In all these categories agricultural machinery takes the lion's share mainly due to the direct emissions that occur during their use, so they confirm to be the weak link in the environmental assessment of the scenarios. FRS and TA categories account for very little of the total impact (around 1\%), while the WC category, which in Scenario A1 is the one with the lowest impact, accounts for $4 \%$ of the impact of Scenario A2.

In overall terms, endpoint analysis indicates that Scenario A1 has an impact of $-10 \%$ compared to Scenario A2 due to savings in irrigation. This means that the benefits of the ideal situation, where water extraction is not required because the 
soil is simply rainfed, can be considered rather limited compared to the overall impact. Moreover, if artificial irrigation is expected to achieve a higher crop yield, this should be at least $10 \%$ higher to be considered more sustainable.

\section{Scenario B}

Scenario B has been built to show the differences between the use of fertilisers (Scenario B1) and the use of animal manure (Scenario B2). Also in this case, the same yield has been assumed to compare the two scenarios with the same FU. From the results of Table 2, it emerges that Scenario B2 has greater impacts in all categories of the ReCiPe method with the exception of FRS (if animal feed is considered, Scenario B2 has greater impacts in this category as well). In some categories (GW and TA) the impacts of Scenario B1 are one-fifth of those of Scenario B2, in others (FPMF and WC) the results are approximately $40 \%$, while in the HT category the impact is $70 \%$. The only exception, as mentioned above, is FRS category, where Scenario B1 has a higher impact than Scenario B2 (49.1 kg oil eq. vs $44.8 \mathrm{~kg}$ oil eq.). The use of fertilisers or manure makes the discussion of the results of Scenario B more complicated than that of Scenario A, so in this case, it is even more useful to look at the contribution to the impact of individual flows (Fig. 4).

As it can be seen from Fig. 4, agricultural machinery and sulphur are responsible for the impacts in Scenario B1. Together they cover more than $94 \%$ of the environmental burden of all impact categories, with sulphur being the first contributor (74\% of the total) of the FRS category impacts. On the other hand, the use of machinery is particularly impactful in the HT category (95\% of the total) and in the other categories, its contribution is around $70 \%$. The reasons for such a high incidence are the same identified in the contribution analysis of Scenario A. Amongst the impacts of the other inputs, the only one worthy of mention is Aton $\mathrm{K} \circledast$ with regard to the impact on the WC category, where it contributes $4 \%$. In all other cases, the contribution to Scenario $\mathrm{B} 1$ impacts of the other inputs is barely observable.

When manure is used as a fertiliser it takes precedence in impact assessment, being the most significant process in the GW, FPMF, TA and WC categories. In these categories, its contribution is $82 \%, 63 \%, 83 \%$ and $65 \%$ of the total, respectively. In the HT category, the contribution from machinery remains the main one ( $70 \%$ of the total), while in the FRS the highest share is that of sulphur (52\% of the total). Including feed production in the process that simulates the use of manure would significantly increase its environmental weight, making it the main factor in the HT and FRS impact categories too.

Since manure has proved to be a product with a high environmental burden that can significantly worsen the impacts of Scenario B, a characterisation analysis was carried out on it in order to understand the reason for this characteristic. The 20 tonnes of animal manure used in Scenario B2 were analysed using the ReCiPe 2016 method and the results are shown in Fig. 5.

As it can be observed, most of the impact lies in the emissions that occur when it is spread on the fields. Almost 70\% of the manure impacts can be attributed to these emissions, while the farming operations and equipment required to cover the remaining $31 \%$. Farming operations include all those actions necessary for the management of animals such as the use of energy and auxiliary materials for lighting,
Fig. 4 Contribution analysis of Scenario B1 and Scenario B2 (ReCiPe 2016 Midpoint)

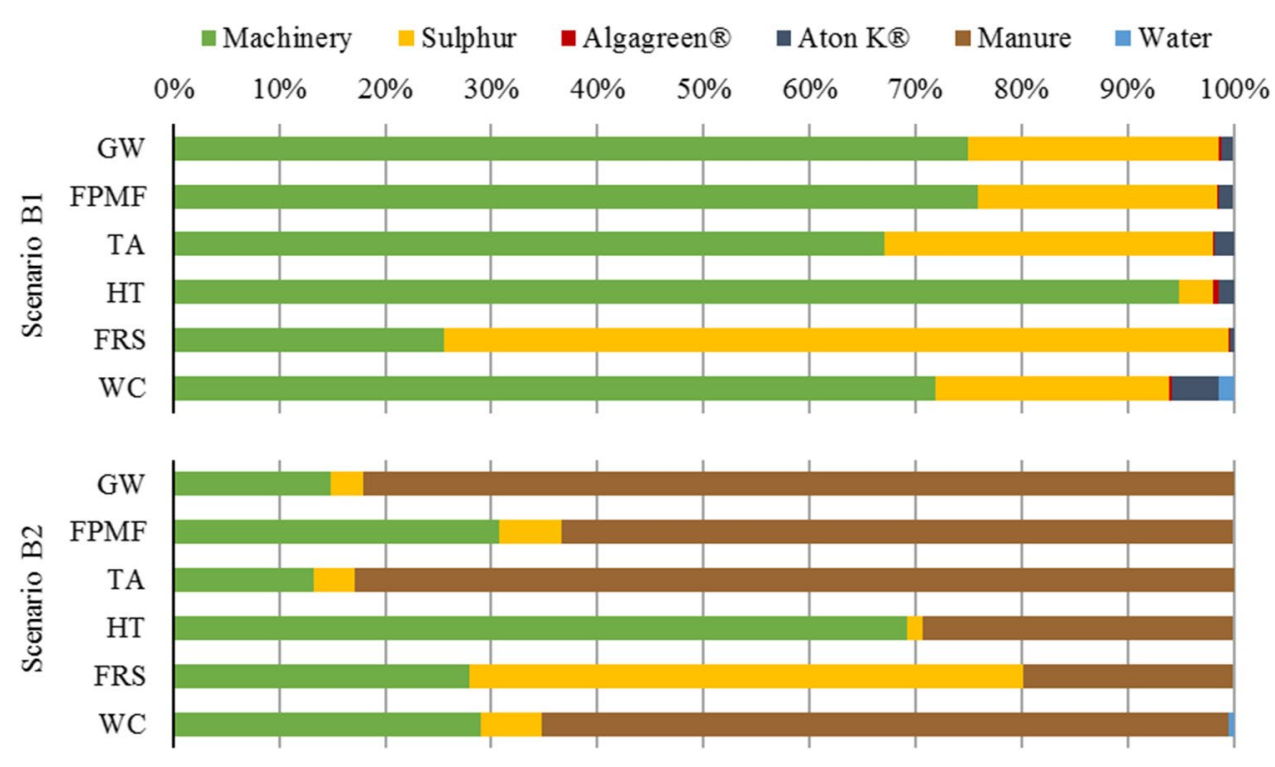




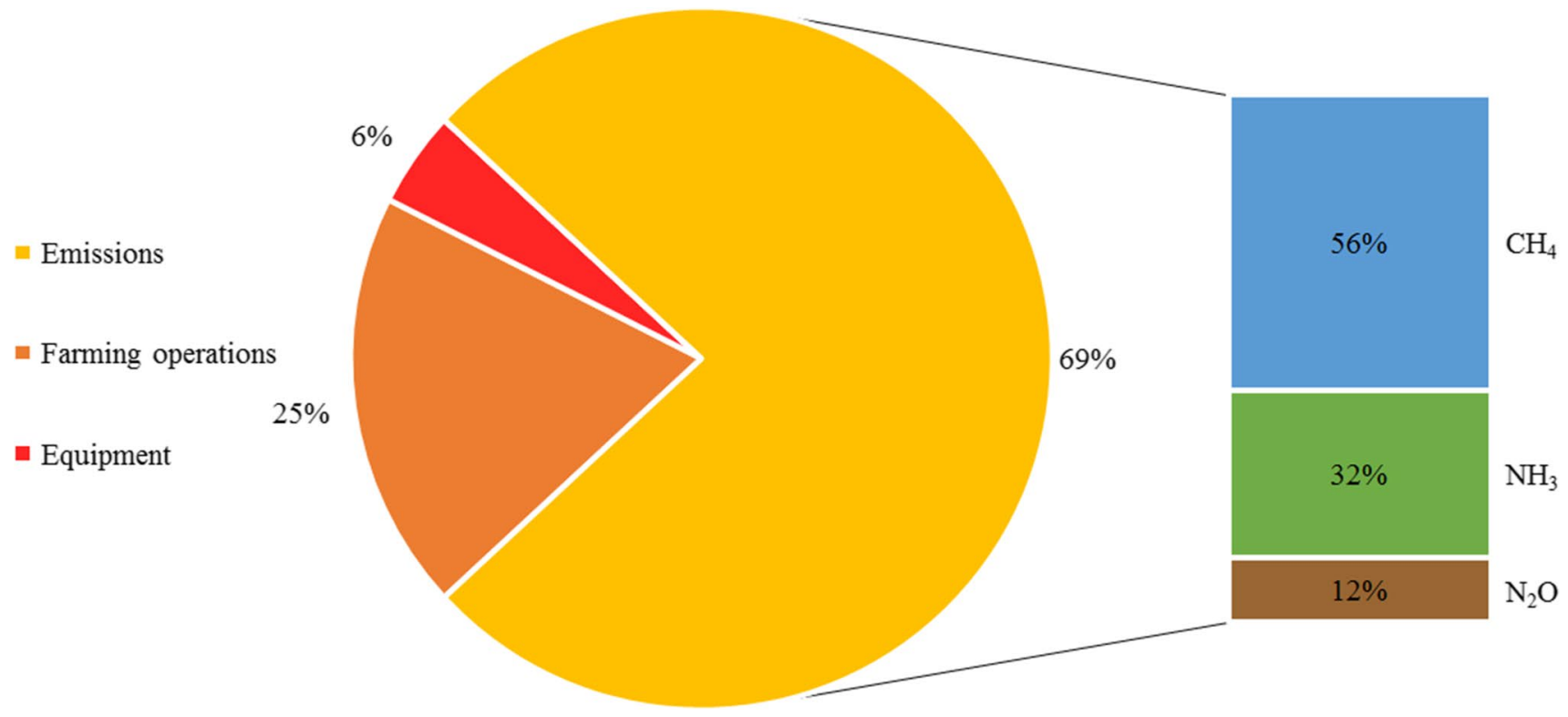

Fig. 5 Analysis of impacts of animal manure (ReCiPe 2016 Endpoint H/A—Single Score)

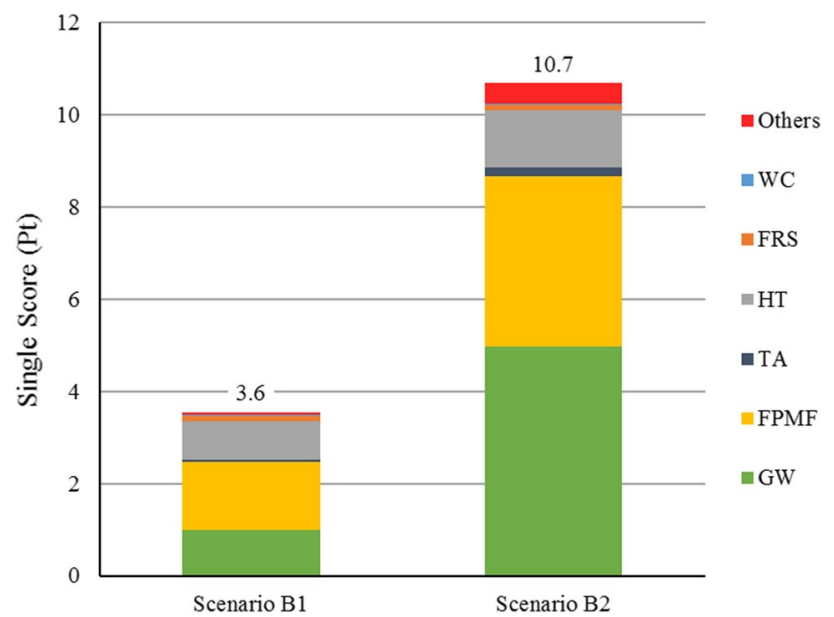

Fig. 6 Single Score results for Scenario B1 and Scenario B2 (ReCiPe 2016 Endpoint H/A)

storage and drying of raw materials, manure scraper, slurry agitator, cleaning, water, etc. It has proven to be an important step in environmental assessment since it accounts for the $25 \%$ of the impacts. The equipment, which includes wood chips and straw used for animal litter, appears to contribute more moderately to the manure's life cycle and covers only $6 \%$ of its impacts. A more detailed analysis of emissions (the weak link of manure) reveals that there are three types of emissions: methane, ammonia and dinitrogen monoxide.
Amongst these, methane is the one with the highest impact because, for 20 tonnes of manure $4.88 \mathrm{~kg}$ of $\mathrm{CH}_{4}, 0.59 \mathrm{~kg}$ of $\mathrm{NH}_{3}$ and $0.12 \mathrm{~kg}$ of $\mathrm{N}_{2} \mathrm{O}$ are emitted. Each gas has its global warming potential (GWP) value which combined with the amount of gas emitted measures its environmental impact. The results show that methane accounts for $56 \%$ of the impact of emissions, which is a well-known environmental problem (Johnson and Johnson 1995), ammonia for 32\% and dinitrogen monoxide for $12 \%$.

As in the previous case, also for Scenario B, an endpoint analysis was carried out to verify which agricultural practice leads to the best environmental performance. The impact values have been translated into single score and the result is shown in Fig. 6.

Scenario B2 has a higher total impact estimated in $10.7 \mathrm{Pt}$ (even $81.4 \mathrm{Pt}$ if animal feed were included in manure production), while Scenario B1 seems to be more sustainable with a score of $3.6 \mathrm{Pt}$. The impacts of the GW, FPMF and HT categories are confirmed to be the most significant for the scenarios, covering more than $90 \%$ of the total impact. The weight of the GW category increases from $28 \%$ of Scenario B1 to $47 \%$ of Scenario B2, as this category, as seen, is strongly affected by the impact of manure. In absolute terms, in fact, the value of GW increases by five times between Scenario B1 and B2. The same, although less evident, can be seen in the FPMF category, whose impact in Scenario B2 is about 2.5 times greater than in Scenario B1. The other categories where manure contribution is dominant are TA 
and WC, but they do not show any particular weight in the overall impact. Finally, the categories where the scenarios show the closest values are HT and FRS, i.e. those where the manure contribution was lower. Moreover, in the FRS category, there is a decrease in impact from Scenario B1 to $\mathrm{B} 2$ because it is dependent on sulphur which is used in lower quantities when manure is applied.

In general, the results of Fig. 6 quantify in $+7.1 \mathrm{Pt}$ $(+200 \%)$ of environmental impact the shift from the use of organic fertilisers (Scenario B1) to animal manure (Scenario B2). If the initial assumption, that a similar yield would finally be obtained notwithstanding the agricultural practice followed, was not confirmed, the same percentage of higher productivity would be achieved by the one employing manure instead of organic fertilisers, to equal the same environmental impact per mass of product.

\section{Scenario C}

The midpoint results of Scenario C (a small and conventional grape processing factory where no organic practices are applied) are collected, together with the others, in Table 2. It must be considered that the same yield is accounted for, by considering only 0.8 ha instead of 1 ha as related to the other scenarios.

Compared to scenarios of Scenario B, the impacts of Scenario $\mathrm{C}$ are greater in all considered impact categories. In some cases, such as FPMF, HT and WC categories, the difference is one order of magnitude, while in the other categories the difference is less marked, especially if compared to Scenario B2. On the other hand, compared to Scenario A, the impacts of Scenario C are closer. In the FRS category, Scenario $C$ shows lower results because they depend on the use of agricultural machinery, which is used less here than in Scenario A (see LCI). The only other exception is WC category, where the impact of Scenario $\mathrm{C}$ is almost half than that of Scenario A2. Nevertheless, in all other categories, Scenario $\mathrm{C}$ has higher values, although in some cases the difference is very small, as in the GW and HT.

Also for Scenario $C$ the contribution analysis (to identify those responsible for the impact) and the endpoint analysis (to assess the total environmental burden) have been carried out. Results are shown in Fig. 7a and b, respectively.

Figure $7 \mathrm{a}$ shows that in all impact categories the environmental weight is borne by the superphosphate, a common fertiliser used in vines. Its contribution ranges from $68 \%$ in the HT category to $89 \%$ in the FRS category and depends mainly on the air emissions of sulphide dioxide that occur during its production chain. Amongst other inputs, the only ones that reach the $10 \%$ contribution to the total are manure in the GW impact category and Cuprocol ${ }^{\circledR}$ in HT, where its contribution peaks at $26 \%$ of the total. Agricultural machinery continues to be an impact constant in almost all categories, although in Scenario $\mathrm{C}$ their contribution never exceeds $7 \%$ of the category. Noteworthy the pesticide Grytos ${ }^{\circledR}$ (described in the system as glyphosate), despite the small amount used, shows modest contributions in the GW and FRS categories.

The endpoint analysis (Fig. 7b) confirms what has already been observed in the other cases, the three main impact categories are GW, FPMF and HT. In this case, the weight of the FPMF category is even greater since it alone covers $49 \%$ of the total of the scenario. The overall impact of Scenario C is estimated at $44.5 \mathrm{Pt}$, of which the HT and GW categories are responsible for $27 \%$ and $19 \%$, respectively.
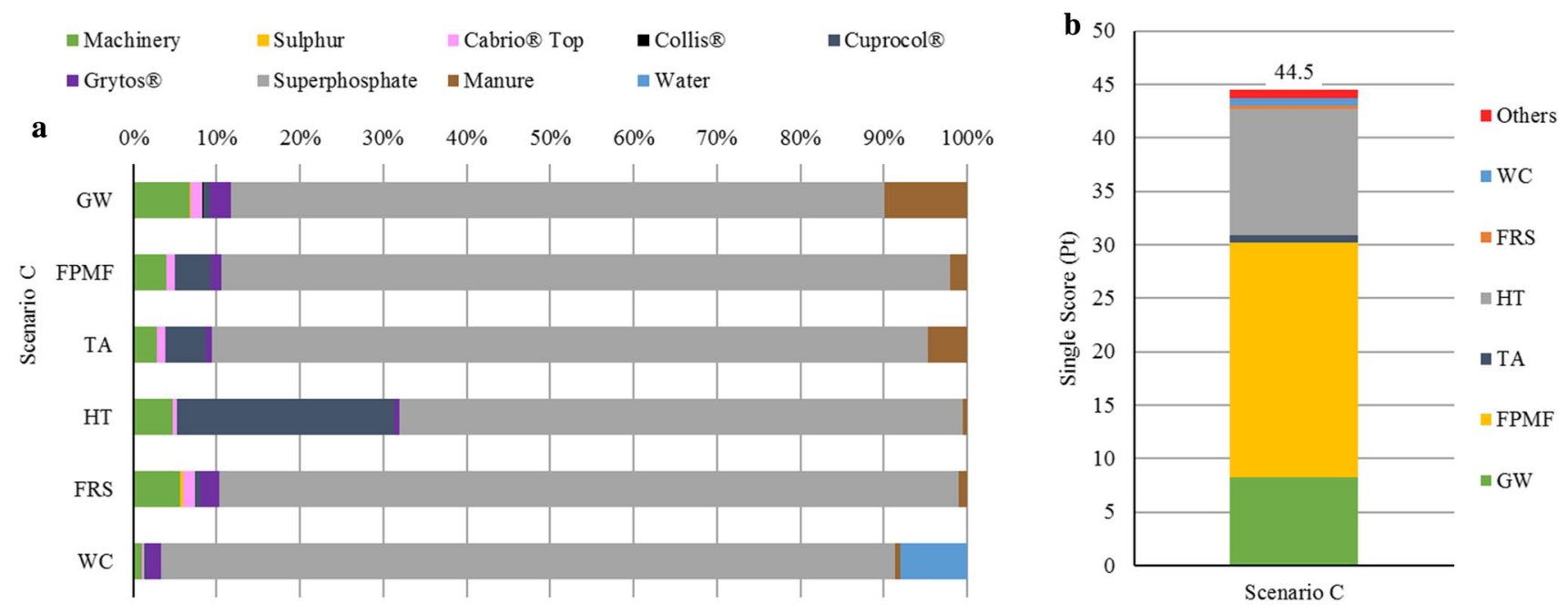

Fig. 7 a Contribution analysis (ReCiPe 2016 Midpoint) and b Single Score results (ReCiPe 2016 Endpoint H/A) for Scenario C 


\section{Comparison between grape processing factories}

Some considerations can be made to understand which agricultural practices could be suggested to improve the sustainability and limit environmental impacts.

For example, the analysis of the impacts of all three grape processing factories showed that the GW, FPMF and HT impact categories are responsible for more than $90 \%$ of the impacts of the scenarios. These categories have already shown a primary incidence in the impact of vineyards (Jourdaine et al. 2020) therefore it is necessary to look mainly at them to improve the environmental performance of crops. Impacts from agricultural machinery proved to be a constant in all analysed scenarios, with particular emphasis in Scenario A where their use is greater than other crops. In Scenario B1 the use of machinery is also the main driver of impacts, but it falls in importance when manure is used as fertiliser. It is precisely with regard to animal manure that controversy emerges from LCA analyses carried out. On the one hand, its use reduces the impacts on FRS category (as synthetic fertiliser production is avoided) and is a way to reuse a material that would otherwise be considered waste (this is one of the simplest and oldest but most successful examples of green and circular economy). On the other hand, it leads to important environmental problems especially related to greenhouse gas emissions when it is spread in the fields. In addition, the fact that superphosphate is primarily responsible for the impacts of traditional cultivation (Scenario C) and that its use is avoided when organic farming practices are adopted is a valid indicator that these practices could aid to achieve a more sustainable production.

Figure 8 shows the total impacts of all scenarios, so as to have a clear and immediate overview of the environmental assessment of the studied grape processing factories.

The results indicate that conventional and non-organic farming practices (Scenario $\mathrm{C}$ ) have a higher environmental impact than organic vineyards (Scenarios A and B), made equal the expected production. In particular, Scenario $\mathrm{C}$ has an estimated impact of $44.5 \mathrm{Pt}$, about $20 \%$ higher than Scenarios A (33.1-36.9 Pt) and 4 and 12 times higher than Scenarios B2 (10.7 Pt) and B1 (3.6 Pt), respectively. This difference, as already seen, lies mainly in the use of superphosphate which alone contributes for 36.0 Pt (see Table S4 in Supporting Information) to the impact of Scenario C.

The study shows that although a $20 \%$ difference between the production of traditional and organic cultivation has been considered, the latter is still preferable from an environmental point of view, even when normalised by the crop yield. If a larger difference in this yield is expected, from the results it is also possible to calculate that the production of Scenario A (calculated in Scenario A1) would be even $40 \%$ lower than the traditional one, maintaining better results from an environmental point of view. Only if the yield of the organic cultivation is less than $40 \%$ compared to the traditional one, then it would be preferable to produce according to conventional methods. In literature the greatest difference in production between traditional and organic vines is quantified in $30 \%$ (Kavargiris et al. 2009), so the conclusion concerning

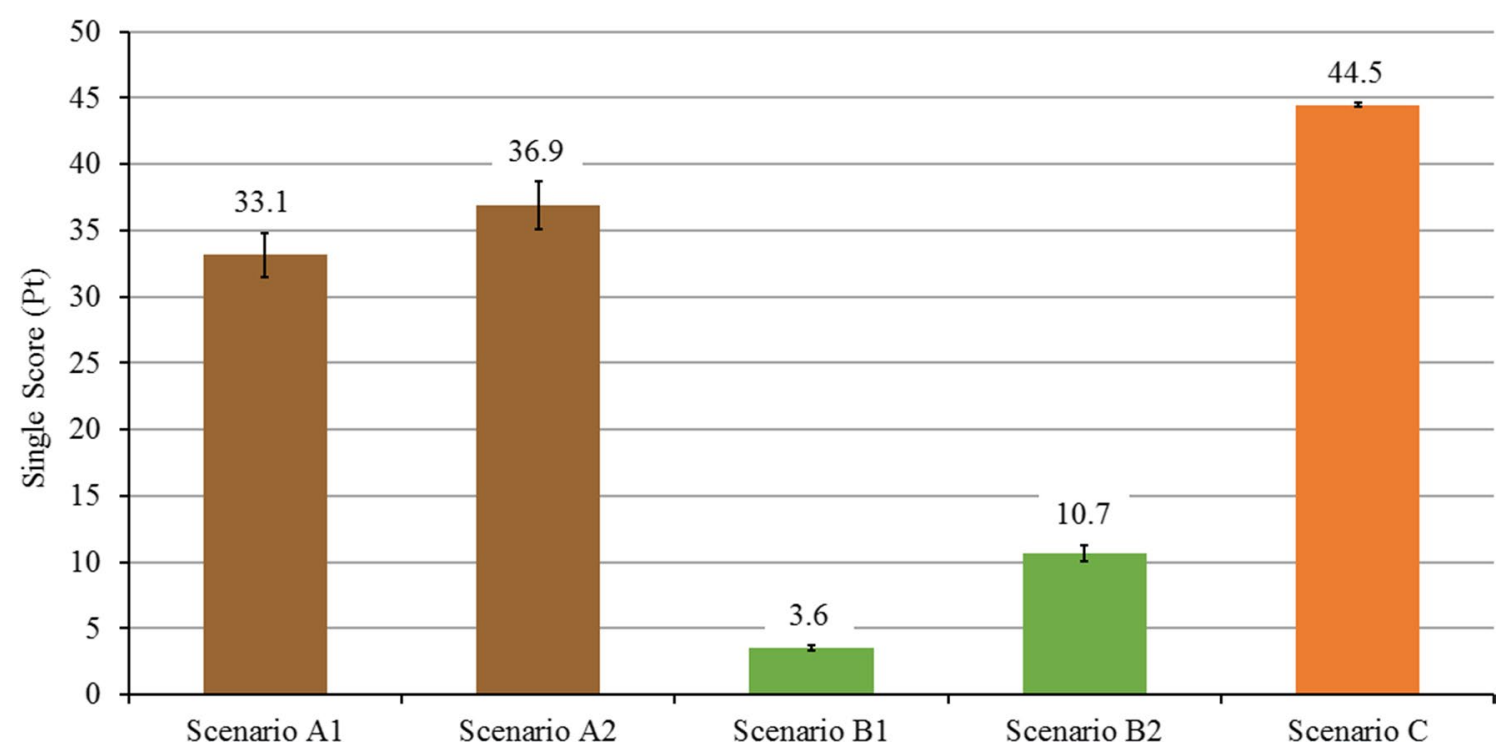

Fig. 8 Comparison of grape processing factories scenarios in terms of ReCiPe 2016 Endpoint H/A—Single Score 
the comparison between organic and conventional drawn in this study can be considered robust.

The comparison between the two organic vineyards shows that Scenario B pursues greener agricultural practices than Scenario A, involving less use of sulphur and less use of agricultural machinery. Even when animal manure is used (which raises the GWP of the Scenario), the impact of vineyard B remains lower than that of vineyard A, indicating a good environmental robustness of the adopted cultivation techniques.

\section{Conclusion}

This study was designed to assess the effect that some biological practices have on the total environmental impact of the vineyards. To do so, two grape processing factories were taken as a case study, whose data were provided directly by the farmers. In the first case (Scenario A) the impact of artificial irrigation was emphasised, while in the second (Scenario B) the focus was on the use of animal manure as fertiliser.

Irrigated organic vine crops (Scenario A2) were found to have a larger ecological footprint than those only rainfed (Scenario A1), even if the difference between the two is small (33.1 Pt vs 36.9 Pt); this would lead to consider the addition of water, if a larger crop yield is expected (>12\%). When the changing variable is the use of manure, it was found that vines using organic fertilisers (Scenario B1) show a much lower total impact than those using manure (Scenario B2). Although manure is considered an organic fertiliser and brings environmental benefits in some aspects, such as the avoided use of fossil resources for the synthesis of chemical fertilisers, its greenhouse gas emissions cause a high impact on global warming, compromising total environmental performance (3.6 Pt vs $10.7 \mathrm{Pt})$. This gap increases when the impacts of animal feed in manure production are considered. Both grape processing factories produce organic grapes, but these aspects could be improved to still ensure that grape production is even more harmless to the environment. Moreover, other changes can be implemented, starting with ensuring that the machinery involved in the cultivation process is used as efficiently as possible, since diesel has played a major role in the impact assessment of organic grape processing factories: $79 \%$ in Scenarios A1, 71\% in Scenario A2, 78\% in Scenario B1 and 26\% in Scenario B2.

In order to contextualise and compare the obtained results for organic crops with traditional ones, the case of a small and conventional grape production has been added to the study (Scenario C), considering the likely increase in productivity. The comparison showed that organic vine crops proved to be more sustainable and environmentally friendly than those considered conventional. In the latter, the use of chemical auxiliaries is common and results in an ecological footprint that can be up to 12 times larger than that of organic crops (when compared to Scenario B1). In conventional vineyard, diesel contributes slightly to the impacts ( $5 \%$ of the total), so in this case, it would be better to focus on reducing the amount of superphosphate used as fertiliser, since it is responsible for $81 \%$ of the total impacts.

In conclusion, the results of this study show that both in organic and conventional crops the use of agricultural machinery and the choice of fertilisers (chemical auxiliaries, fertilizers, etc.) have a great influence on the carbon footprint balance. Therefore, they are crucial points that need to be meticulously addressed for a proper review of agricultural practices in order to move towards less impacting scenarios.

Since these grapes are used to produce organic grape products further investigations will be devoted to assessing how much the different use of manure and water affect the harvest, since a greater productivity would probably compensate for a larger ecological footprint. Looking into the grape processing industry with a "cradle-to-grave" approach would also be useful for grape processing factories, since it might be helpful to understand steps with higher critical points in terms of environmental impact (not only the grape growing and production stages but also the other phases that follow until the final grape processed production). Changing the key factors identified by this expansion of the study would naturally lead to a "greener" grape processed production and could be implemented (relatively easily) together with the measures mentioned above to meet objectives requested by a sustainable development. Finally, this work should be considered as an attempt to get closer to the grape processing factories and to support their choices during the cultivation of the vineyards. People working in the private sector need a quick way to verify the sustainability of their choices and start thinking about implementing the best solutions.

Supplementary Information The online version contains supplementary material available at https://doi.org/10.1007/s13762-021-03688-2.

Acknowledgements This study was performed thanks to the collaboration between the Department of Industrial Chemistry of the University of Bologna and the Department of Earth Physics \& Thermodynamics of the University of Valencia, which fully funded and supported the development of the project.

Funding Open access funding provided by Alma Mater Studiorum Università di Bologna within the CRUI-CARE Agreement. 
Open Access This article is licensed under a Creative Commons Attribution 4.0 International License, which permits use, sharing, adaptation, distribution and reproduction in any medium or format, as long as you give appropriate credit to the original author(s) and the source, provide a link to the Creative Commons licence, and indicate if changes were made. The images or other third party material in this article are included in the article's Creative Commons licence, unless indicated otherwise in a credit line to the material. If material is not included in the article's Creative Commons licence and your intended use is not permitted by statutory regulation or exceeds the permitted use, you will need to obtain permission directly from the copyright holder. To view a copy of this licence, visit http://creativecommons.org/licenses/by/4.0/.

\section{References}

Aranda A, Zabalza I, Scarpellini S (2005) Economic and environmental analysis of the wine bottle production in Spain by means of life cycle assessment. Int J Agric Resour Gov Ecol 4:178. https://doi. org/10.1504/IJARGE.2005.007199

Arzoumanidis I, Raggi A, Petti L (2014) Considerations when applying simplified LCA approaches in the wine sector. Sustainability 6:5018-5028. https://doi.org/10.3390/su6085018

Avadí A (2020) Screening LCA of French organic amendments and fertilisers. Int J Life Cycle Assess 25:698-718. https://doi.org/10. 1007/s11367-020-01732-w

Benedetto G (2013) The environmental impact of a Sardinian wine by partial life cycle assessment. Wine Econ Policy 2:33-41. https:// doi.org/10.1016/J.WEP.2013.05.003

Beylot A, Villeneuve J (2017) Accounting for the environmental impacts of sulfidic tailings storage in the life cycle assessment of copper production: a case study. J Clean Prod 153:139-145. https://doi.org/10.1016/j.jclepro.2017.03.129

Borsato E, Zucchinelli M, D'Ammaro D et al (2020) Use of multiple indicators to compare sustainability performance of organic vs conventional vineyard management. Sci Total Environ 711:135081. https://doi.org/10.1016/j.scitotenv.2019.135081

Brockmann D, Pradel M, Hélias A (2018) Agricultural use of organic residues in life cycle assessment: current practices and proposal for the computation of field emissions and of the nitrogen mineral fertilizer equivalent. Resour Conserv Recycl 133:50-62. https:// doi.org/10.1016/j.resconrec.2018.01.034

Cano Londoño NA, Velásquez HI, McIntyre N (2019) Comparing the environmental sustainability of two gold production methods using integrated emergy and life cycle assessment. Ecol Indic 107:105600. https://doi.org/10.1016/j.ecolind.2019.105600

Cespi D, Passarini F, Vassura I, Cavani F (2016) Butadiene from biomass, a life cycle perspective to address sustainability in the chemical industry. Green Chem 18:1625-1638. https://doi.org/ 10.1039/C5GC02148K

Civit B, Piastrellini R, Curadelli S, Arena AP (2018) The water consumed in the production of grapes for vinification (Vitis vinifera). Mapping the blue and green water footprint. Ecol Indic 85:236243. https://doi.org/10.1016/j.ecolind.2017.10.037

Clark M, Tilman D (2017) Comparative analysis of environmental impacts of agricultural production systems, agricultural input efficiency, and food choice. Environ Res Lett 12:064016. https:// doi.org/10.1088/1748-9326/aa6cd5
Colomb V, Ait SA, Mens CB et al (2015) AGRIBALYSE®, the French LCI Database for agricultural products: high quality data for producers and environmental labelling. OCL Oilseeds Fats 22:D104. https://doi.org/10.1051/ocl/20140047

Comandaru IM, Bârjoveanu G, Peiu N et al (2012) Life cycle assessment of wine: focus on water use impact assessment. Environ Eng Manag J 11:533-543

Dantsis T, Douma C, Giourga C et al (2010) A methodological approach to assess and compare the sustainability level of agricultural plant production systems. Ecol Indic 10:256-263. https:// doi.org/10.1016/J.ECOLIND.2009.05.007

de Pablo VJ, Román Sánchez IM (2011) La importancia de la denominación de origen en la industria vitivinícola española. Cienc ErgoSum 18:135-144

Falk B (2013) The resilient farm and homestead : an innovative permaculture and whole systems design approach. Chelsea Green Publishing UK Ltd, South Wing, Somerset House Strand London WC2R 1LA

Gazulla C, Raugei M, Fullana-i-Palmer P (2010) Taking a life cycle look at crianza wine production in Spain: where are the bottlenecks? Int J Life Cycle Assess 15:330-337. https://doi.org/10. 1007/s11367-010-0173-6

Gold M V (1999) Sustainable agriculture: definitions and terms. Alternative farming systems information center, U.S. Department of Agriculture

Herath I, Green S, Singh R et al (2013) Water footprinting of agricultural products: a hydrological assessment for the water footprint of New Zealand's wines. J Clean Prod 41:232-243. https://doi. org/10.1016/j.jclepro.2012.10.024

Hillis V, Lubell M, Hoffman M (2018) Sustainability partnerships and viticulture management in California. J Environ Manag 217:214 225. https://doi.org/10.1016/j.jenvman.2018.03.033

Holland T, Smit B (2010) Climate change and the wine industry: current research themes and new directions. J Wine Res 21:125-136. https://doi.org/10.1080/09571264.2010.530095

Huijbregts M, Steinmann ZJN, Elshout PMFM et al (2016) ReCiPe 2016. Natl Inst Public Heal Environ. https://doi.org/10.1007/ s11367-016-1246-y

Iannone R, Miranda S, Riemma S, De Marco I (2016) Improving environmental performances in wine production by a life cycle assessment analysis. J Clean Prod 111:172-180. https://doi.org/ 10.1016/j.jclepro.2015.04.006

ISO (2006a) ISO 14040:2006 - Environmental management — Life cycle assessment - Principles and framework. https://www.iso. org/standard/37456.html. Accessed 5 Nov 2020

ISO (2006b) ISO 14044:2006 - Environmental management - Life cycle assessment - Requirements and guidelines. https://www. iso.org/standard/38498.html. Accessed 5 Nov 2020

Jezierska-Tys S, Wesołowska S, Gałąka A et al (2020) Biological activity and functional diversity in soil in different cultivation systems. Int J Environ Sci Technol 17:4189-4204. https://doi.org/ 10.1007/s13762-020-02762-5

Johnson KA, Johnson DE (1995) Methane emissions from cattle. J Anim Sci 73:2483-2492. https://doi.org/10.2527/1995.7382483x

Jourdaine M, Loubet P, Trebucq S, Sonnemann G (2020) A detailed quantitative comparison of the life cycle assessment of bottled wines using an original harmonization procedure. J Clean Prod 250:119472-119515

Kavargiris SE, Mamolos AP, Tsatsarelis CA et al (2009) Energy resources' utilization in organic and conventional vineyards: 
energy flow, greenhouse gas emissions and biofuel production. Biomass Bioenerg 33:1239-1250. https://doi.org/10.1016/j.biomb ioe.2009.05.006

Koch P, Salou T (2016) AGRIBALYSE®: Rapport Méthodologique - Version 1.3

Lacirignola M, Blanc P, Girard R et al (2017) LCA of emerging technologies: addressing high uncertainty on inputs' variability when performing global sensitivity analysis. Sci Total Environ 578:268280. https://doi.org/10.1016/j.scitotenv.2016.10.066

Liang L, Wang Y, Ridoutt BG et al (2019) Agricultural subsidies assessment of cropping system from environmental and economic perspectives in North China based on LCA. Ecol Indic 96:351360. https://doi.org/10.1016/j.ecolind.2018.09.017

Malusà E, Laurenti E, Ghibaudi E, Rolle L (2004) Influence of organic and conventional management on yield and composition of Grape cv. "Grignolino." In: Acta Horticulturae. International Society for Horticultural Science, pp 135-141. https://doi.org/10.17660/ ActaHortic.2004.640.15

Marette S (2005) The collective-quality promotion in the agribusiness sector: an overview, Midwest Agribusiness Trade Research and Information Center (MATRIC) Publications (archive only) 05-wp406, Center for Agricultural and Rural Development (CARD) at Iowa State University

Marshall RS, Cordano M, Silverman M (2005) Exploring individual and institutional drivers of proactive environmentalism in the US Wine industry. Bus Strateg Environ 14:92-109. https://doi.org/ $10.1002 /$ bse. 433

Mohammadi J, South W (2017) Life cycle assessment (LCA) of benchmark concrete products in Australia. Int J Life Cycle Assess 22:1588-1608. https://doi.org/10.1007/s11367-017-1266-2

Moran W (1993) Rural space as intellectual property. Polit Geogr 12:263-277. https://doi.org/10.1016/0962-6298(93)90057-E

Neri E, Passarini F, Cespi D et al (2018) Sustainability of a bio-waste treatment plant: Impact evolution resulting from technological improvements. J Clean Prod 171:1006-1019. https://doi.org/10. 1016/j.jclepro.2017.10.082

Notarnicola B, Tassielli G, Nicoletti GM (2003) Life cycle assessment (LCA) of wine production. In: Mattsson B, Sonesson U (eds) Environmentally-friendly food processing. A volume in Woodhead Publishing Series in Food Science, Technology and Nutrition, Elsevier, pp 306-326
Otto S, Loddo D, Baldoin C, Zanin G (2015) Spray drift reduction techniques for vineyards in fragmented landscapes. J Environ Manag 162:290-298. https://doi.org/10.1016/j.jenvman.2015.07.060

Peters JF, Baumann M, Zimmermann B et al (2017) The environmental impact of Li-Ion batteries and the role of key parameters- $\mathrm{A}$ review. Renew Sustain Energy Rev 67:491-506

Petti L, Ardente F, Bosco S et al (2010) State of the art of life cycle assessment (LCA) in the wine industry. In: Conference proceedings of the 7th international conference on life cycle assessment in the agri-food sector, vol. 1. Cassano delle Murge (Ba): Serigrafia Artistica Pugliese Solazzo s.r.1.; 2010. pp 493-498. JRC58529

Piccinno F, Hischier R, Seeger S, Som C (2018) Predicting the environmental impact of a future nanocellulose production at industrial scale: application of the life cycle assessment scale-up framework. J Clean Prod 174:283-295. https://doi.org/10.1016/j.jclepro.2017. 10.226

Pizzigallo ACI, Granai C, Borsa S (2008) The joint use of LCA and emergy evaluation for the analysis of two Italian wine farms. J Environ Manag 86:396-406. https://doi.org/10.1016/j.jenvman. 2006.04.020

Point E, Tyedmers P, Naugler C (2012) Life cycle environmental impacts of wine production and consumption in Nova Scotia, Canada. J Clean Prod 27:11-20. https://doi.org/10.1016/J.JCLEP RO.2011.12.035

PRé Consultants (2020) SimaPro. SimaPro v.9.1 Softw.

Quirós R, Villalba G, Gabarrell X, Muñoz P (2015) Life cycle assessment of organic and mineral fertilizers in a crop sequence of cauliflower and tomato. Int J Environ Sci Technol 12:3299-3316. https://doi.org/10.1007/s13762-015-0756-7

Renaud-Gentié C, Dijkman TJ, Bjørn A, Birkved M (2015) Pesticide emission modelling and freshwater ecotoxicity assessment for Grapevine LCA: adaptation of PestLCI 2.0 to viticulture. Int J Life Cycle Assess 20:1528-1543. https://doi.org/10.1007/ s11367-015-0949-9

Ricciardi M, Passarini F, Vassura I et al (2017) Glycidol, a valuable substrate for the synthesis of monoalkyl glyceryl ethers: a simplified life cycle approach. Chemsuschem 10:2291-2300. https://doi. org/10.1002/cssc. 201700525

Román Sánchez IM, Belmonte-Ureña LJ (2013) Appraisal of environmental regulations on sustainable consumption of water in the wine-producing Spanish industry. Environ Eng Manag J 12:1979-1987 
Rugani B, Vázquez-Rowe I, Benedetto G, Benetto E (2013) A comprehensive review of carbon footprint analysis as an extended environmental indicator in the wine sector. J Clean Prod 54:61-77. https://doi.org/10.1016/j.jclepro.2013.04.036

Sabeen AH, Kamaruddin SNB, Noor ZZ (2019) Environmental impacts assessment of industrial wastewater treatment system using electroless nickel plating and life cycle assessment approaches. Int J Environ Sci Technol 16:3171-3182. https://doi.org/10.1007/ s13762-018-1974-6

Seufert V, Ramankutty N, Foley JA (2012) Comparing the yields of organic and conventional agriculture. Nature 485:229-232. https://doi.org/10.1038/nature11069

Sinisterra-Solís NK, Sanjuán N, Estruch V, Clemente G (2020) Assessing the environmental impact of Spanish vineyards in UtielRequena PDO: the influence of farm management and on-field emission modelling. J Environ Manag 262:301-4797. https://doi. org/10.1016/j.jenvman.2020.110325

Stoessel F, Juraske R, Pfister S, Hellweg S (2012) Life cycle inventory and carbon and water foodprint of fruits and vegetables: application to a swiss retailer. Environ Sci Technol 46:3253-3262. https://doi.org/10.1021/es2030577

Trinh LTK, Hu AH, Lan YC, Chen ZH (2020) Comparative life cycle assessment for conventional and organic coffee cultivation in Vietnam. Int J Environ Sci Technol 17:1307-1324. https://doi.org/10. 1007/s13762-019-02539-5

Tsapekos P, Khoshnevisan B, Alvarado-Morales M et al (2019) Environmental impacts of biogas production from grass: role of co-digestion and pretreatment at harvesting time. Appl Energy 252:113467. https://doi.org/10.1016/j.apenergy.2019.113467

USDA (1980) Report and recommendations on organic farming. USDA Study Team on Organic Farming United Stated department of Agriculture

van der Giesen C, Cucurachi S, Guinée J et al (2020) A critical view on the current application of LCA for new technologies and recommendations for improved practice. J Clean Prod 259:120904. https://doi.org/10.1016/j.jclepro.2020.120904

Villanueva-Rey P, Vázquez-Rowe I, Moreira MT, Feijoo G (2014) Comparative life cycle assessment in the wine sector: biodynamic vs. conventional viticulture activities in NW Spain. J Clean Prod 65:330-341. https://doi.org/10.1016/J.JCLEPRO.2013.08.026

Villanueva-Rey P, Vázquez-Rowe I, Otero M et al (2015) Accounting for time-dependent changes in GHG emissions in the Ribeiro appellation (NW Spain): are land use changes an important driver? Environ Sci Policy 51:215-227. https://doi.org/10.1016/J. ENVSCI.2015.04.001

Willer H, Schlatter B, Travnicek J et al (2020) The world of organic agriculture: statistics and emerging trends 2020. 21st edn. Research Institute of Organic Agriculture (FiBL) and IFOAM Organics International, Frick and Bonn

Zhao G, Ruan D, Wang Q et al (2018) Systemic boundaries in industrial systems: a new concept defined to improve LCA for metallurgical and manufacturing systems. J Clean Prod 187:717-729. https://doi.org/10.1016/j.jclepro.2018.03.263 